\title{
Research on Capital Structure Optimization and Capital Operation
}

\author{
Liu Xiaoyao
}

\author{
Xi'an International University, Business school, Xi'an, Shaanxi ,China
}

\author{
Keywords: Capital Structure Optimization, Capital Operation
}

\begin{abstract}
Capital structure refers to the proportion of total liabilities and owner's equity of all capital sources of enterprises and their proportion. Capital structure is the core problem of enterprise financing decision-making and it is an important part of corporate finance. Irrational capital structure directly affects the production and operation of enterprises and it is related to the survival of enterprises. Therefore, enterprises must optimize the capital structure through various channels, reduce the cost of capital to get the maximum value of the enterprise.
\end{abstract}

\section{Introduction}

Nowadays, under the environment of socialist market economy, the capital operation of enterprises has very important economic effect and significance in the process of market competition and operation. Capital operation is the enterprise resources and production of the configuration of the overall planning, planning and optimization. Scientific and reasonable capital operation and the adjustment of property right structure of enterprises can provide environmental support for maximizing the economic efficiency of enterprises, and promote the formation of large-scale investment, financing and economic scale, thus further disperse the operational risks and investment risks. To reduce the role of enterprise risk, to achieve scientific and rational allocation of enterprise resources and optimize the structure of property rights adjustment, and promote enterprise leaps and bounds in the progress and development. However, in the actual operation of enterprise development, because of market regulation, information asymmetry and other reasons, the enterprise's capital operation and property rights structure, there is a single, imperfect, is not conducive to sustainable development of enterprises.

\section{The Definition of Corporate Capital Operation}

Capital operation, as the name suggests, refers to the use of assets in the form of monetized enterprises as the object of purchase, transaction, operation, investment and financing activities, is the pursuit of maximizing profits and economic benefits of important capital operation. At a certain level, enterprises can use less capital investment or increase the amount of capital, can achieve good economic returns and controllable assets. Enterprises can attract investment and increase enterprise operation funds through their own development advantages and characteristics of the industry, etc. In addition, enterprises can carry out the space transfer of capital and promote enterprises to transfer from the unfavorable position to the enterprises' can increase the value of the position of the dull capital of the enterprise to play a role in the activation of the capital to invigorate the enterprise, can effectively improve the efficiency of the use of corporate capital to achieve the maximization of capital value and enterprise value maximization.

\section{The Existing Problems in the Enterprises Capital Operation and the Capital Structure Optimization}

Lack of capital operation experience and one-sided pursuit of diversification of property rights structure. As the traditional concept of the impact of the original business in the capital operation of the business concept and mode of operation and so there are still some limitations, cannot fully meet the needs of market economy development; the same time, Chinese market economy is still in the development stage, there are some limitations, leading to a lack of capital 
operating system environment and perfect market environment, and as capital operation is still in its infancy, lack of relevant professional experience, resulting in the capital operation and ownership structure decision-making process there is a certain blind But because of the lack of capital operation experience, leading to serious problems in the process of mergers and reorganization of enterprises in the process of mergers and acquisitions of enterprises, the lack of capital operating experience, Resulting in corporate capital debt and other serious business risk and financial risk.

Capital operation lack of well-organized intermediary organizations. Capital operation Because of its complexity, specialization and risk, the intermediary organization plays an important role in capital operation and plays an important role in capital operation. Intermediary organizations in the capital operation process mainly to the information decision-makers to provide real and reliable decision-making information to the relevant enterprises to provide advice and broaden the financing channels for enterprises. However, due to the market environment constraints and the lack of professional talents, the intermediary organizations in the actual capital operation do not fully play its due value, to assume due responsibilities and tasks. At the same time, the intermediary organization in the operation process lacks the perfect organization mechanism as well as the rules and regulations, causes some intermediary organization's behavior not standard, even deceives investor and so on the question.

Lack of capital operation and property rights structure is too single. Due to the changing market environment and the special environment of market development in China, enterprises are confronted with large financial risks, information risks and management risks in the capital operation. As a result, the enterprises in the capital operation process due to information asymmetry, Capital operating costs and high capital turnover rate and other issues and thereby inhibiting the capital operation in the mode of operation and operational means to achieve a breakthrough. At the same time, enterprises in the development process, due to the influence of the original traditional planned economy, resulting in the adjustment of property rights issues cannot be long-term perspective, but too much emphasis on a single public ownership, leading to state-owned property rights in the enterprise As well as the proportion of corporate ownership, resulting in the structure of property rights is too single cannot truly realize the diversification of industrial structure.

\section{The Measures for Enterprise Capital and Property Rights Structure Optimization}

Sound and improve the capital operation, promote the real diversity of enterprise property rights institutions. The development of enterprises will go through different stages, so in different stages of development, enterprises should be based on their own actual situation, the status quo and the development of strategic objectives and external market, industry environment, practical, tailored to scientific and rational capital operation plans and programs in line with their actual needs. Enterprises through horizontal and vertical mergers, restructuring, mergers and other means of a reasonable combination, and further improve the business capital operation. For example, an enterprise in the actual capital operation process, that is, from the horizontal and vertical direction for different combinations of capital and property rights structure of the adjustment and optimization, one direction is through a combination of the way to attract small and medium enterprises to invest And investment, the use of shares of the way the replacement of assets, the application of less capital transactions, to achieve the optimization of enterprise property rights and resource allocation. Another direction is through the use of equity distribution system, so that business managers and technical staff can use the purchase of shares to participate in the management and operation of enterprises, not only to achieve the outstanding management personnel and technical personnel use to achieve the enterprise's property structure optimization, through such a way of recruiting talent, help to improve the enthusiasm and creativity of employees, and stimulate the enthusiasm of the staff, thus promoting the work efficiency and quality improvement, and strengthen the cohesion of the enterprise, thereby enhancing the overall strength of enterprises and enterprises the competitiveness of enterprises to achieve a win-win situation. 
Change the way of capital operation thinking to create a good environment for optimizing the structure of property rights. In order to better realize the operation of enterprise capital and optimize the structure of property rights, an enterprise must gradually change the mode of thinking in the process of capital operation and rationally expand the operation of enterprise capital. In order to improve the operation and development of enterprises, of the strategic thinking, not just that the capital operation of enterprises is to issue shares or buy stock holding so one-sided way, but should the economic transformation of business management ideas and ideas, to give up the inherent inherently narrow capital operation philosophy and way of thinking, and asked to abandon the old outdated only rely on the comprehensive market-related ideas, innovative, bold to accept the capital operation of multi-level and diversified development trend. Enterprises should actively use the social capital operation, plan and step by step to upgrade and optimize the property right structure of enterprises, to provide a scientific, orderly and planned external market economy environment for the optimization of property rights structure, to achieve the enterprise property rights structure Diversified to create appropriate conditions. At the same time, enterprises should also be in line with its own actual situation and characteristics of the rapid development of the development, low-cost high-speed hands of a return of capital operating system, and constantly improve and perfect the enterprise's property structure, to achieve enterprise cash flow efficiency and quality for enterprise capital operation of health, good operation to provide support and protection.

Establish and improve enterprise property rights operation mechanism. At present, the property right contact of our country enterprise has a degree of solidification, which affects the development of the enterprise. Therefore, the transformation of the ownership structure of enterprises must follow the production and management of enterprises, management activities, investment and financing activities such as the occurrence of economic capital, change and change. Therefore, the reasonable operation mechanism of enterprise property right structure is an important component of enterprise capital operation and development. The operating mechanism of enterprise property right structure is embodied in two aspects: (1) It should include the use mechanism of enterprise property rights, the use of the process can be sufficient, scientific and rational and effective management rules and regulations and management principles and objectives; (2) it should also take into account the transfer of property rights mechanisms, corporate property rights structure is with the continuous development of enterprises and the market environment so that enterprises need to establish a reasonable and perfect mechanism of enterprise property rights transfer to ensure that the enterprise property rights structure can be fully with their own actual situation, development and development strategies and prospects to adapt to, and then promote the enterprise property rights structure, Which is the important way for the property right structure of the enterprise to play a comprehensive property right benefit. It must be grasped by the enterprises' property right main body and finally realize the good capital operation and optimization of the enterprise. Property rights structure, and promote the rational allocation of resources and leap-forward progress and development.

Establish a centralized and large-scale enterprise. development of enterprises and enhance the competitiveness of enterprises, must start from their own position, increase the role of capital operation and intensity of enterprises, to build a capital-based link, through the formation of a competitive market economy, there are advantages of cross-regional cross-sector and cross-mechanism of enterprise groups and promote the optimization of corporate property rights structure, to achieve corporate finance and investment diversification of the main. To do this work, first of all, should have the industry advantage, development potential and comprehensive strength of the company as the core, and actively play the effectiveness of market economy, through different forms of property rights, such as: mergers, acquisitions, these enterprises do Large and strong, the formation of large-scale, competitive enterprises; secondly, is the implementation of strategic alliances between enterprises, the implementation of both competition and cooperation model, to achieve economic and social benefits of a win-win situation. At the same time, based on the combination of enterprises, it is necessary to actively change the concept and ideas, and actively communicate and communicate with multinational companies to improve their technical level; Finally, through the intangible capital, expansion of enterprise capital, Business name brand, 
management and marketing advantages, product advantages, industry advantages, expand the capital of the operating channels.

Training professional personnel and improve the intermediary institutions. At present, the strength and advantages of enterprises not only reflect the first capital and property rights structure, but also lies in the enterprise's high-tech talent and high-level management personnel, enterprises must pay attention to the introduction of capital professionals and training, building unity and efficiency The intermediary organizations in the enterprise's capital operation has an important role, mainly for enterprises to improve the accurate and effective information, consulting, capital processing, asset evaluation and financing of the company's capital operation, methods and other services. Therefore, it is necessary to establish and perfect the system of intermediaries, to formulate scientific and reasonable intervention system, evaluation standards, information management system, so as to enhance the credibility and normality of intermediary organizations, and to increase support and guarantee for enterprises in capital operation.

\section{Conclusion}

At present, enterprises should constantly improve the capital operation mode, change the concept and way of enterprise capital operation thinking, and further deepen and perfect enterprise property structure, optimize and adjust the allocation of enterprise resources, improve the economic and social benefits of production and operation, so that the self-advantage of enterprises in the market competition is guaranteed, it can be fully in a larger area and scope of the capital and production factors, enhance the scale of the enterprise value and economic benefits, the maximum reduction of corporate capital operation and production management in the risk and cost, and promote the comprehensive strength and competitiveness of enterprises and ultimately the sustainable development of enterprises.

\section{References}

[1] B. N. Ma, Research on enterprise capital operation and property right structure optimization, J. Chinese and Foreign Entrepreneurs. 44 (2010) 146-147.

[2] H.X.Zeng, Research on capital operation and property right structure optimization of coal enterprises, J. Finance and Economics. 18(2005) 55-57.

[3] J.H.Xue, Study on state - owned capital operation, J. Coastal Economy, 32(2012) 189-190.

[4] Y.J.Qi, Analysis of the relationship between the capital operation of coal enterprises and the optimization of property right structure, J. Coal Economic Management, 4(2007) 38-40.

[5] Y.M.Tian, Enterprise theory and the structure of enterprise property right, J. Southern Economy, 9(2013) 142-150. 